\title{
Precisão dimensional de moldes de hidrocoloide irreversível manipulado com solução de clorexidina
}

\author{
Dimensional accuracy of irreversible hydrocolloid impressions \\ manipulated with chlorhexidine solution
}

\author{
Carmem Dolores Vilarinho Soares de Moura* \\ Lorenna Bastos Lima Verde Nogueira* \\ Valdimar da Silva Valente* \\ Janaína Cordeiro de Oliveira* \\ Alana de Alencar Bezerra** \\ Ana Claúdia Santos Rodrigues ${ }^{* * *}$
}

\section{Resumo}

Objetivo: avaliar a precisão dimensional de modelos de gesso obtidos em moldes de hidrocoloide irreversível contendo agente antimicrobiano, manipulado com água ou solução aquosa de digluconato de clorexidina 0,2\%. Materiais e método: para as medições das dimensões lineares, foram utilizados moldes de hidrocoloide irreversível de um modelo mestre de aço inox, simulando preparos de uma prótese fixa com dois pilares separados por um espaço protético. Com esses moldes, obteve-se vinte modelos de gesso designados aos grupos: controle - modelos de gesso obtidos em moldes de hidrocoloide irreversível contendo clorexidina no pó manipulado com água destilada $(n=10)$; experimental - modelos de gesso obtidos em moldes de hidrocoloide irreversível contendo clorexidina no pó e manipulado com solução de clorexidina em substituição à água (n = 10). As distâncias entre pilares e os diâmetros dos pilares foram mensuradas com paquímetro digital e os dados, submetidos ao teste $t$ student. Resultado: as medições das distâncias entre pilares e do diâmetro dos pilares dos modelos do grupo experimental não resultaram em diferenças dimensionais estatisticamente significantes quando comparadas com as do grupo controle ( $p>0,05)$. Conclusão: de acordo com os resultados deste estudo e considerando as suas limitações, pôde-se concluir que as diferenças dimensionais entre modelos de gesso obtidos com moldes de hidrocoloide irreversí- vel manipulado com água ou com solução aquosa de digluconato de clorexidina a $0,2 \%$ não foram estatisticamente significantes.

Palavras-chave: Clorexidina. Materiais para moldagem odontológica. Prótese dentária.

\section{Introdução}

$\mathrm{Na}$ impossibilidade de uso do processo clássico de esterilização nos moldes da cavidade bucal, a desinfecção química com soluções desinfetantes vem sendo utilizada e discutida em relação aos materiais de moldagem. $\mathrm{O}$ hidrocoloide irreversível (alginato), por exemplo, apresenta limitações quanto ao processo de desinfecção por imersão do molde na solução desinfetante, considerando que a natureza hidrófila desse material exige um limite de tempo de contato com os líquidos desinfetantes ${ }^{1,2}$. No entanto, alguns estudos relatam que técnicas de imersão, spray ${ }^{3}$ e nebulização de hipoclorito de sódio $0^{4,5}$ mostraram-se métodos eficazes do ponto de vista microbiológico e da precisão dimensional.

\footnotetext{
Doutor(a), Universidade Federal do Piauí, Departamento de Odontologia Restauradora, Teresina, Piauí, Brasil.

Mestre, Universidade Federal do Piauí, Teresina, Piauí, Brasil.

* Acadêmica de graduação, Universidade Federal do Piauí, Teresina, Piauí, Brasil.
} 
A eficácia já comprovada da clorexidina, decorrente das propriedades bacteriostáticas (em baixas concentrações) e bactericidas (em altas concentrações), reduz os microrganismos no ambiente oral e inibe a formação de placa, tornando-a um importante antimicrobiano a ser usado como coadjuvante na redução de infecção cruzada ${ }^{6}$. O mercado disponibiliza alginatos suplementados com clorexidina, e alguns estudos têm sido feitos utilizando a solução aquosa de digluconato de clorexidina a $0,2 \%$ como líquido de mistura ${ }^{7-9}$. Essa técnica tem como vantagem específica o combate da contaminação proporcionada pelos microrganismos orais que são facilmente incorporados, no ato da moldagem, durante a geleificação do alginato. A imersão ou aplicação do desinfetante como spray proporcionaria somente um efeito superficial ${ }^{8}$.

Embora, nas pesquisas que utilizam autodesinfecção do hidrocoloide irreversível com clorexidina, os resultados não atinjam 100\% de eficácia antimicrobiana, a redução da contaminação é bastante significativa ${ }^{7,10}$, restando ainda a opção de fazer desinfecção complementar nos modelos de gesso ${ }^{11}$. Outro insucesso clínico, quando do uso de alginato, estaria relacionado com o acondicionamento dos moldes e tempo entre moldagem e vazamento do gesso $^{12}$. Na busca de precisão dimensional e de qualidade superficial dos modelos de gesso vazados em moldes de alginato, também, tem-se desenvolvido alginatos que permitem vazamento tardio ${ }^{13}$.

A proposta desse experimento foi avaliar a precisão dimensional dos modelos de gesso obtidos em moldes de hidrocoloide irreversível contendo diacetato de clorexidina no pó, manipulado com água ou com solução aquosa de digluconato de clorexidina a $0,2 \%$.

\section{Materiais e método}

A amostra deste experimento foi constituída por vinte modelos $(\mathrm{n}=10)$ de gesso tipo IV (Elite Rock ${ }^{\circledR}$ - Zermack, Polesine, Rovigo, Itália, lote 81859), obtidos a partir de moldes de hidrocoloide irreversível (HI) de um modelo mestre de aço inox. Como variável resposta, foi avaliada a precisão dimensional dessas unidades em relação aos grupos: controle - modelos de gesso obtidos em moldes de HI Jeltrate Chromatic ${ }^{\circledast}$ (Dentsply Indústria e Comércio Ltda., Petrópolis, Rio de Janeiro, Brasil, lote 301695 C), contendo diacetato de clorexidina na sua composição (pó) e manipulado com água destilada na temperatura de $23^{\circ} \mathrm{C}$; experimental - modelos de gesso obtidos em moldes de HI Jeltrate Chromatic ${ }^{\circledR}$, manipulado com solução aquosa de digluconato de clorexidina a 0,2\% (Virgínia Regina Fortes Castelo Branco e Cia Ltda., Farmácia Galeno de Manipulação, Teresina, Piauí, Brasil) na temperatura de $23^{\circ} \mathrm{C}$, em substituição à água.
O modelo mestre de aço inox utilizado representou preparos de uma prótese fixa com dois pilares e um espaço protético de $20 \mathrm{~mm}$ (Figura 1). Os pilares foram identificados como pilar A (5 mm de diâmetro) e pilar B (7 mm de diâmetro), conforme os valores médios referenciados nos diâmetros das coroas dentárias ${ }^{14}$, simulando preparos para coroa total, com término cervical em forma de degrau inclinado em 135 graus, respeitando a angulação cérvico-oclusal menor que 8 graus ${ }^{15}$.

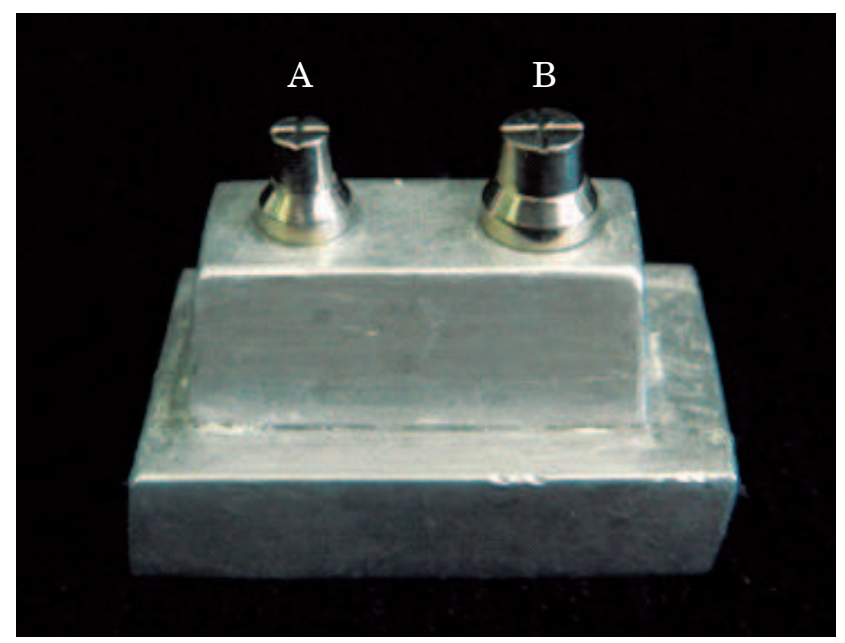

Figura 1 - Modelo mestre com pilares identificados

Foram confeccionadas moldeiras personalizadas em aço inox para o modelo mestre e o conjunto fixado em um verticulador (Bio-Art ${ }^{\circledR}$, SN-09354, São Carlos, São Paulo, Brasil) para permitir movimento uniforme somente no sentido vertical, e, assim, todos os moldes foram obtidos com o mesmo padrão (Figura 2).

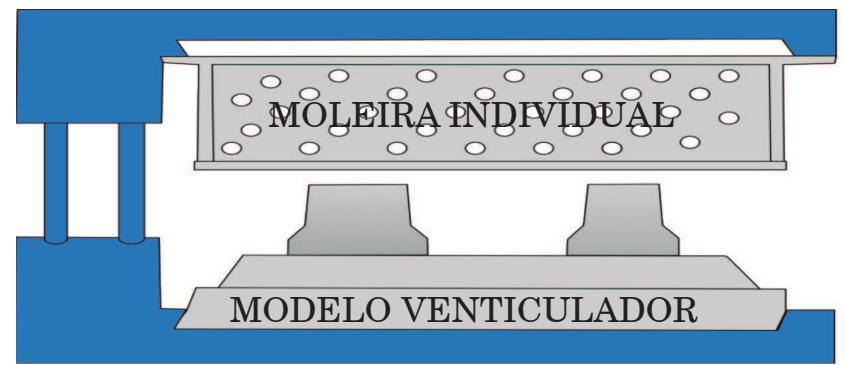

Figura 2 - Conjunto utilizado para moldagem (verticulador, moldeira individual e modelo mestre)

A umidade do ar presente durante a confecção dos modelos foi estabelecida dentro de parâmetros recomendados pela Especificação $\mathrm{n}^{\circ} 25$ da ADA $(2000)^{16}$, em que a variação consiste em $50 \pm 10 \%$. Já a temperatura ambiente foi padronizada no intervalo de 21 a $23^{\circ} \mathrm{C}$. O HI, por sua vez, foi dosado e espatulado segundo instruções de uso do fabricante. Para sua manipulação, utilizou-se cuba de silicone, espátula e medidores de pó e água. Os moldes obtidos foram acondicionados em uma caixa umidificadora até o momento do vazamento (10 minutos) para evitar sinérese do hidrocoloide irreversível ${ }^{5}$, simulando o tempo clínico necessário para lavagem 
do molde, desinfecção adicional e preparo do gesso em laboratório.

O vazamento do molde foi realizado com gesso tipo IV (Elite Rock, Zermack, Polesine, Rovigo, Itália, lote 81859) dosado na relação água/pó $6 \mathrm{~mL} / 25$ $\mathrm{g}$, adicionando o pó à água, mexendo discretamente por alguns segundos e, então, espatulado a vácuo (VACUMIXER $^{\circledR}$, Polidental Indústria e Comércio Ltda., 06714-285 Cotia, São Paulo, Brasil) por 20 segundos. O gesso espatulado foi colocado no molde em incrementos, com o auxílio de uma espátula $\mathrm{n}^{\circ} 7$ e vibrador (DCL - Dentária Campineira Ltda., Campinas, São Paulo, Brasil), para aumentar a fluidez do material no molde.

$\mathrm{O}$ gesso permaneceu por 45 minutos em contato com o molde, sendo esse conjunto armazenado em uma caixa umidificadora ${ }^{17}$. Após a separação molde-modelo, os modelos foram selecionados utilizando o critério de ausência de bolhas e fraturas no gesso. Os modelos selecionados foram recortados e limpos com água destilada em ultrassom (Cristófoli Equipamentos de Biossegurança Ltda., Campos Mourão, Paraná, Brasil, SN USC090323), durante 15 segundos, para remoção dos resíduos de gesso decorrentes do recorte. Em seguida, foram identificados, selados com filme PVC e acondicionados em caixas fechadas até o momento da leitura.

Decorridas 48 horas da confecção dos modelos, foram feitas as medidas das distâncias entre os pilares A e B, tendo como referência as extremidades externas no topo de cada pilar (Figura 3-a), como também o diâmetro individual de cada pilar em relação às dimensões vestíbulo-linguais e mesiodistais (Figura 3-b). Utilizou-se, para esses procedimentos, paquímetro digital Mitutoyo ${ }^{\circledR}$ com resolução 0,01 - 150 mm/6" (Mitutoyo Sul Americana, 08620-000 Susano, São Paulo, Brasil). Cada medição foi repetida seis vezes pelo mesmo operador, resultando num valor médio.

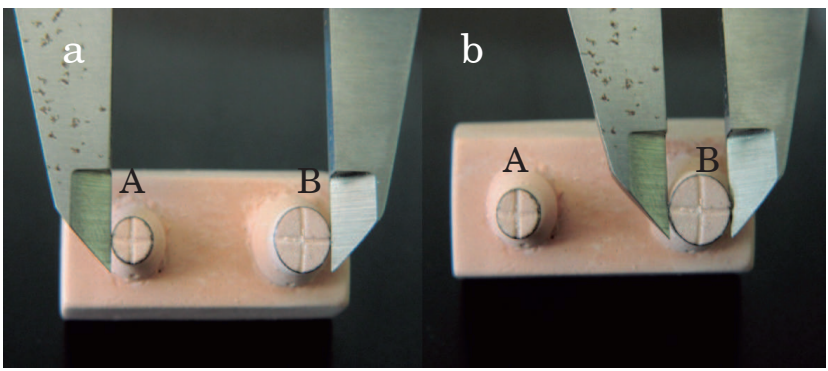

Figura 3 - a) Medida da distância entre os pilares A-B e b) Medida do diâmetro do pilar B

O processamento e a análise dos dados foram realizados no programa SPSS ${ }^{\circledR}$, versão 18.0 (International Business Machines - IBM, Rio de Janeiro, Brasil). Inicialmente, aplicou-se o teste de Shapiro- Wilk para avaliar a normalidade das variáveis. Para verificar diferença entre as médias dos grupos, utilizou-se teste $t$ student, sendo considerado estatisticamente significativo um valor de $\mathrm{p}<0,05$.

\section{Resultados}

Os resultados estão descritos na Tabela 1 . Verificou-se que as medições das distâncias entre os pilares e do diâmetro dos pilares dos modelos de gesso do grupo experimental não resultaram em diferenças dimensionais estatisticamente significativas quando comparadas com as do grupo controle ( $p$ $>0,05)$.

Tabela 1 - Média, desvio padrão $(d p)$ e $p$ - valor dos diâmetros dos pilares $A$ e $B$ e distância A-B em milímetros $(\mathrm{mm})$

\begin{tabular}{l|c|c|c}
\cline { 2 - 3 } & Controle & Experimental & $\begin{array}{c}\text { Pédia }(\mathrm{dp}) \\
\text { valor* }\end{array}$ \\
\cline { 2 - 3 } & Média $(\mathrm{dp})$ & valor \\
\hline Diâmetro pilar A & $4,93(0,02)$ & $4,93(0,03)$ & 0,581 \\
Diâmetro pilar B & $6,93(0,02)$ & $6,92(0,06)$ & 0,540 \\
Distância A-B & $25,80(0,04)$ & $25,80(0,04)$ & 0,946 \\
\hline
\end{tabular}

* Teste t student

\section{Discussão}

Diante das evidências de que as soluções desinfetantes podem alterar a precisão dimensional e a qualidade da superfície dos moldes de HI, trazendo consequências aos modelos de gesso ${ }^{18,19}$, alternativas têm sido propostas para minimizar essas alterações. A autodesinfecção dos moldes de HI, mediante a adição de clorexidina no pón ôn $^{3,20,21}$ ou como solução para mistura ${ }^{7-10,22}$, mostrou-se eficaz na redução da contaminação em muitos estudos. Avaliou-se, nesse experimento, a precisão dimensional dos pilares de modelos de gesso obtidos com moldes de HI contendo diacetato de clorexidina no pó e manipulado com solução aquosa de digluconato de clorexidina a $0,2 \%$. Quando comparados aos modelos de gesso decorrentes de moldes de HI manipulados com água, as diferenças dimensionais entre os grupos não foram estatisticamente significantes.

A solução de digluconato de clorexidina a $0,2 \%$ foi considerada a mais recomendada como substituto da água na manipulação do alginato, devido à sua comprovada ação bactericida e biocompatibilidade $^{10,22}$ com os tecidos intraorais. Outro estudo relatou que o uso de uma solução aquosa de digluconato de clorexidina a $0,2 \%$ para manipulação de alginato foi melhor do que a incorporação de $0,05 \%$ de diacetato de clorexidina no pó, em termos de redução da contaminação apresentada pelos moldes ${ }^{7}$. Ainda nesse estudo, os autores consideram que os sais de clorexidina apresentam solubilidades diferentes no estado líquido e em pó, de forma que a solução de digluconato foi mais eficaz, caracterizando que o diacetato de clorexidina (pó) é menos solúvel que o digluconato. Neste experimento, utilizou-se a associação do desinfetante no pó e no líquido de mistura do HI e comprovou-se que a precisão dimensional dos modelos de gesso vazados nesses moldes 
não apresentou variações significativas; no entanto, não foi avaliada a possibilidade de a clorexidina interferir nas propriedades físicas do gesso, tais como dureza e textura superficial.

A técnica de autodesinfecção do alginato utilizada neste experimento tem a vantagem específica de combater a contaminação dos microrganismos orais que podem ser incorporados no material de moldagem durante a sua geleificação $0^{8,23} \mathrm{e}$, mesmo não sendo $100 \%$ eficaz no combate aos microrganismos, possibilita um molde com menor carga microbiana, facilitando os procedimentos posteriores de desinfecção. O uso da clorexidina com o objetivo de minimizar a carga microbiana aderida aos moldes de HI foi relatado em estudo do qual o bochecho com solução de clorexidina previamente à obtenção de moldes de HI demonstrou redução da sua contaminação, sendo a concentração de $0,2 \%$ mais eficaz quando comparada à de $0,12 \%^{24}$.

Alguns métodos têm sido propostos para descontaminar os modelos de gesso, tais como imersão em solução de hipoclorito de sódio a $0,525 \%{ }^{11}$ ou incorporação de soluções desinfetantes no ato da mistura do gesso ${ }^{25}$. No entanto, esses métodos têm resultado em alterações nas propriedades dos gessos, tais como menor resistência à compressão e menor dureza superficial ${ }^{26-28}$. Estudo investigando alterações nas propriedades físicas dos gessos com adição de soluções desinfetantes de glutaraldeído $2 \%$, povidone-iodine $10 \%$, gluconato de clorexidina $0,2 \%$ e hipoclorito de sódio $1 \%$ mostrou que o gluconato de clorexidina alterou a dureza superficial do gesso e a expansão de presa ${ }^{29}$. Portanto, seria recomendável a realização de estudos que avaliassem se a presença de clorexidina no molde afetaria as propriedades físicas do gesso nele vazado.

\section{Conclusão}

De acordo com os resultados obtidos neste estudo e considerando as suas limitações, pôde-se concluir que a precisão dimensional dos modelos de gesso obtidos com moldes de HI manipulado com solução de clorexidina a $0,2 \%$ não foi diferente dos modelos do grupo controle.

\section{Abstract}

Objective: to assess the dimensional accuracy of plaster casts obtained from irreversible hydrocolloid impressions containing anti-microbial agent, which was mixed with either water or $0.2 \%$ chlorhexidine digluconate aqueous solution. Materials and method: the linear dimensions were measured with irreversible hydrocolloid impressions of a stainless steel master cast simulating cavity preparations for a fixed prosthesis with two abutments separated by a prosthetic space. From these molds, twenty plaster casts were made and assigned to the following groups: control - plaster casts obtained from irreversible hydrocolloid impressions made with powder containing chlorhexidine, and manipulated with distilled water $(n=10)$; experimental - plaster casts obtained from irreversible hydrocolloid impressions made with powder containing chlorhexidine, and manipulated with chlorhexidine solution instead of water $(n=10)$. The distances between the abutments and their diameters were measured with a digital caliper and data were submitted to the Student's t test. Result: there were no statistically significant differences in the measurements of distances between the abutments and their diameter in the experimental group when compared to the measurements of the control group ( $p>0.05)$. Conclusion: according to the results of this study and considering its limitations, the dimensional differences between plaster casts obtained from irreversible hydrocolloid impressions manipulated with either water or $0.2 \%$ chlorhexidine digluconate were not statistically different.

Keywords: Chlorhexidine. Dental impression materials. Prosthodontics.

\section{Referências}

1. Taylor RL, Wright OS, Maryan C. Disinfection procedures: their effect on the dimensional accuracy and surface quality of irreversible hydrocolloid impression materials and gypsum casts. Dent Mater 2002; 18(2):103-10

2. Supromo MS, Kattadiyil MT, Goodacre CJ, Winer MS. Effect of disinfetant on irreversible hydrocolloid and alternative impression materials and the resultant gypsum casts. J Prosthet Dent 2012; 108:250-8.

3. Lemos IS, Porto RO, Alves BP, Jassé FF, Galvão MR, Andrade MF, et al. avaliação da alteração dimensional de modelos obtidos a partir de moldagens com alginato tradicional e outro com desinfetante. Rev Odontol UNESP 2010; 39(1):41-7.

4. Moura CDVS, França FMG, Martins GAS, Nogueira LBLV, Zanetti RV. Disinfection of irreversible hydrocolloid impressions with sodium hypochlorite steam: assessment antimicrobial efficacy. Rev Odont Cienc 2010; 25(2):182-9.

5. Moura CDVS, Moura, WL, França FMG, Martins GAS, Feltrin PP, Zanetti RV. Disinfection of irreversible hydrocolloid impressions with sodium hypochlorite steam: Assessment of surface roughness and dimensions of gypsum models. Rev Odont Cienc 2010; 25(3):276-81.

6. Hortense SR, Carvalho ES, Carvalho FS, Silva RPR, Bastos JRM, Bastos RS. Chlorhexidine use as a preventive and therapeutic agent in dentistry. Rev Odontol Univ Cid São Paulo 2010; 22(2):178-84.

7. Casemiro LA, Pires-de-Souza FCP, Panzeri H, Martins $\mathrm{CHG}$, Ito IY. In vitro antimicrobial activity of irreversible hydrocolloid impressions against 12 oral microorganisms. Braz Oral Res 2007; 21(4):323-9.

8. Wang J, Wan Q, Chao Y, Chen Y. A self-disinfecting irreversible hydrocolloid impression material mixed with chlorhexidine Solution. Angle Orthodontist 2007; 77(5):894-900.

9. Flanagan DA, Palenik CJ, Setcos JC, Miller CH. Antimicrobial activities of dental impression materials. Dent Mater 1998; 14:399-404. 
10. Touyz LZG, Rosen M. Disinfection of alginate impression material using disinfectants as mixing and soak solutions. J Dent 1991; 19:255-5.

11. Abdullah MA. Surface detail, compressive strength and dimensional accuracy of gypsum casts after repeated immersion in hypochlorite solution. J Prosthet Dent 2006; 95(6):462-8.

12. Barbosa GAS, Carvalho BX, Seabra EJG, Lima IPC. Avaliação da estabilidade dimensional do alginato em relação ao tempo entre moldagem, vazamento e acondicionamento do molde. PCL Rev Bras Prot Clin Lab 2003; 5(24):133-7.

13. Nassar U, Aziz T, Flores-Mir C. Dimensional stability of irreversible hydrocolloid impression materials as a function of pouring time: a systematic review. J Prosthet Dent 2011; 106:126-33.

14. Goodacre CJ, Campagni WV, Aquilo SA. Tooth preparations for complete crowns: an art form based on scientific principles. J Prosthet Dent 2001; 85(4):363-76.

15. Inoue RT, Zanetti AL, Feltrin PP, Farias FAR. Nova técnica de referência para preparos dentais denominada Inoue \& Zanetti. Rev Assoc Paul Cir Dent 2001; 55(6):431-6.

16. American National Standarts Institute. American Dental Association. ANSI/ADA specification $\mathrm{n}^{0} 25$ for dental gypsum products. New York: American National Standarts Institute; 2000.

17. Araújo JEJ, Moraes JV. Alginato: armazenamento em cuba umidificadora e tratamento de superfície. Rev Bras Odontol 1993; L(3):38-41.

18. Santos GC. Avaliação das propriedades físico-mecânicas de um gesso tipo IV submetido a métodos de desinfecção. Parte II - rugosidade superficial e estabilidade dimensional. Cienc Odontol Bras 2003; 6:31-5.

19. Silva SMLM, Salvador MCG. Effect of the disinfection technique on the linear dimensional stability of the dental impression materials. J Appl Oral Sci 2004; 12(3):244-9.

20. Cserna A, Crist RL, Adams AB, Dunning DG. Irreversible hydrocolloids: a comparison of antimicrobial efficacy. $\mathrm{J}$ Prosthet Dent 1994; 71:387-9

21. Esteves RA, Sousa EG, Celestino Júnior AF, Maranhão KM, Pedrosa SS, Gauch LMR. Análise da eficácia antimicrobiana dos alginatos autodesinfetantes. RGO 2007; 55(1):23-8.

22. Rosen M, Touyz LZG. Influence of mixing disinfectant solutions into alginate on working time and accuracy. J Dent $1991 ; 19: 186-8$.

23. Breault LG, Paul JR, Hondrum SO, Christensen LC. Die stone disinfection: incorporation of sodium hypochlorite. J Prosthodont 1998; 7:13-6.

24. Moura CDVS, Nogueira LBLV, Nascimento CC, Soares IMV, Castro JCO, Moura WL. Microbiological assessment of the effectiveness of chlorhexidine mouthinse before taking impressions of the oral cavity. Rev Odonto Cienc 2012; 27(2):156-60.

25. Rentzia A, Coleman MJ, O’Donnell MJ, Dowling AH, O'Sullivan M. Disinfection procedures: their efficacy and effection dimensional accuracy and surface quality of on irreversible hydrocolloid impression material. J Dent 2011; 39:133-40.

26. Boden J, Likeman P, Clark R. Some effects of disinfecting solutions on the propeties of alginate impression material and dental Stone. Eur J Prosthodont Res Dent 2001; 9:131-5.
27. Abdelaziz KM, Combe EC, Hodges JS. The effect of disinfectant on the properties of dental gypsum: Mechanical propeties. J Prosthodont 2002; 11(3):161-7.

28. Scaranelo RM, Bombanatti PE, Rister RP, Bombanatti R, Bombanatti JFS. Efeito de soluções desinfetantes cloradas na resistência à compressão e dureza superficial dos gessos. PCL 2004; 6(30):159-65.

29. Ivanovski S, Savage NW, Brockhurst PJ, Bird OS. Disinfection of dental stone casts: antimicrobial effects and physical property alterations. Dent Mater 1995; 11(1):19-23.

Endereço para correspondência:

Carmem Dolores Vilarinho Soares de Moura Rua Miosótis, 1837, Bairro Jockey

64048- 130 Teresina, $\mathrm{PI}$

Fone: (86) 3223-5252

E-mail: carmemdvsm@uol.com.br

Recebido: 11/06/2013. Aceito: 03/10/2013. 